ARTICLE

Received 13 May 2015 | Accepted 20 Oct 2015 | Published 20 Nov 2015

DOI: $10.1038 /$ ncomms9951

OPEN

\title{
Soluble LR11/SorLA represses thermogenesis in adipose tissue and correlates with BMI in humans
}

\author{
Andrew J. Whittle ${ }^{1, \star}$, Meizi Jiang ${ }^{2,3, \star}$, Vivian Peirce ${ }^{1}, J^{\prime}$ ana Relat ${ }^{4}$, Sam Virtue ${ }^{1}$, Hiroyuki Ebinuma ${ }^{5}$, \\ Isamu Fukamachi ${ }^{5}$, Takashi Yamaguchi ${ }^{6}$, Mao Takahashi ${ }^{7}$, Takeyoshi Murano ${ }^{2}$, Ichiro Tatsuno ${ }^{6}$, \\ Masahiro Takeuchi ${ }^{8}$, Chiaki Nakaseko ${ }^{8}$, Wenlong Jin ${ }^{9}$, Zhehu Jin ${ }^{10}$, Mark Campbell ${ }^{1}$, Wolfgang J. Schneider ${ }^{11}$,

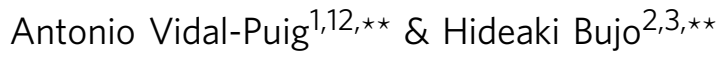

Thermogenesis in brown adipose tissue (BAT) is an important component of energy expenditure in mammals. Recent studies have confirmed its presence and metabolic role in humans. Defining the physiological regulation of BAT is therefore of great importance for developing strategies to treat metabolic diseases. Here we show that the soluble form of the low-density lipoprotein receptor relative, LR11/SorLA (sLR11), suppresses thermogenesis in adipose tissue in a cell-autonomous manner. Mice lacking LR11 are protected from diet-induced obesity associated with an increased browning of white adipose tissue and hypermetabolism. Treatment of adipocytes with SLR11 inhibits thermogenesis via the bone morphogenetic protein/TGF $\beta$ signalling pathway and reduces Smad phosphorylation. In addition, sLR11 levels in humans are shown to positively correlate with body mass index and adiposity. Given the need for tight regulation of a tissue with a high capacity for energy wastage, we propose that LR11 plays an energy conserving role that is exaggerated in states of obesity.

\footnotetext{
${ }^{1}$ University of Cambridge Metabolic Research Laboratories, Level 4, Wellcome Trust-MRC Institute of Metabolic Science, Box 289, Addenbrooke's Hospital, Cambridge CB2 OQQ, UK. ${ }^{2}$ Department of Clinical-Laboratory and Experimental-Research Medicine, Toho University, Sakura Medical Center, Sakura 2858741, Japan. ${ }^{3}$ Department of Genome Research and Clinical Application, Chiba University Graduate School of Medicine, Chiba 260-8670, Japan.

${ }^{4}$ Department of Biochemistry and Molecular Biology, School of Pharmacy, University of Barcelona, and Institute of Biomedicine of the University of Barcelona (IBUB), Barcelona 08028, Spain. ${ }^{5}$ Tsukuba Research Institute, Sekisui Medical Co. Ltd., Ryugasaki 301-0852, Japan. ${ }^{6}$ Center for Diabetes, Endocrinology and Metabolism, Toho University, Sakura Medical Center, Sakura 285-8741, Japan. ${ }^{7}$ Cardiovascular Center, Toho University, Sakura Medical Center, Sakura $285-$ 8741, Japan. ${ }^{8}$ Department of Hematology, Chiba University Hospital, Chiba 260-8677, Japan. ${ }^{9}$ Department of Endocrinology, Affiliated Hospital of Yanbian University, Yanji 133000, China. ${ }^{10}$ Department of Dermatology, Affiliated Hospital of Yanbian University, Yanji 133000, China. ${ }^{11}$ Department of Medical Biochemistry, Medical University of Vienna, Max F. Perutz Laboratories, Vienna 1030, Austria. ${ }^{12}$ Department of Cellular Genetics, Wellcome Trust Sanger Institute, Hinxton, Cambridge CB10 1SA, UK. * These authors contributed equally to this work. ${ }^{\star}$ These authors jointly supervised this work. Correspondence and requests for materials should be addressed to A.V.-P. (email: ajv22@medschl.cam.ac.uk) or to H.B. (email: hideaki.bujo@med.toho-u.ac.jp).
} 
$\mathrm{M}$ urine studies have demonstrated that increasing heat production in brown adipose tissue (BAT) can offset obesogenic effects of a high-fat diet $(\mathrm{HFD})^{1,2}$, whereas reducing thermogenesis exacerbates them ${ }^{3}$. The existence of BAT in adult humans has been 'reconfirmed' by using modern imaging techniques and tissue biopsies ${ }^{4-6}$, increasing the importance of understanding BAT's physiological regulation. In addition, levels of detectable BAT correlate negatively with age, body mass index (BMI) and diabetes ${ }^{7}$, and using intermittent cold exposure to increase amounts of BAT is sufficient to increase post-prandial energy expenditure and improve insulin sensitivity ${ }^{8}$. Collectively, these findings support the hypothesis that thermogenesis in BAT is an important factor contributing to human metabolism. Numerous secreted and circulating factors have been identified to date with the ability to enhance the amount and/or activity of BAT $^{9}$. Given the need for tight regulation of a tissue with such a high capacity for energy wastage, it is somewhat surprising that comparatively few negative regulators have been described. Changes in levels of LR11 in humans have primarily been associated with Alzheimer's disease, linked to its potential role in amyloid processing in the brain ${ }^{10}$. More recently, LR11 has been shown to possess the required properties of a functional lipoprotein receptor and the soluble form (sLR11) has been shown to facilitate increased vascular smooth muscle cell migration in response to injury, hinting at an equally important peripheral role $\mathrm{e}^{11-13}$. LR11 has also been shown to regulate lipoprotein lipase (LPL), a key enzyme regulating the supply of lipid to BAT, by coordinating both its anterograde and retrograde vesicular transport ${ }^{14,15}$.

Here we show that mice lacking LR11 are protected from dietinduced obesity because of a hypermetabolic phenotype, facilitated by enhanced thermogenic gene expression in white adipose tissue (WAT) depots. Our data demonstrate that sLR11 is able to bind to bone morphogenetic protein (BMP) receptors and suppress thermogenic signalling via suppression of downstream Smad protein phosphorylation. The expression profile of $\operatorname{Lr} 11$ and serum levels of sLR11 in mice increase at times of increased thermogenesis, suggesting a regulatory role of sLR11 in preventing excessive energy wastage. sLR11 levels correlate with adiposity in humans, leading us to conclude that sLR11 may be an important negative regulator of adipose tissue energy expenditure, which is dysregulated in obesity, potentially compromising metabolic responses to nutritional stimuli.

\section{Results}

$\mathrm{Lr}^{-1} \mathrm{I}^{-/}$mice are hypermetabolic and protected from obesity. We previously generated a mouse lacking LR11 to examine its role in vascular smooth muscle cells in vivo and that of the cleaved soluble form (sLR11) in vitro ${ }^{11,16}$. These studies highlighted a tendency for $\operatorname{Lr11^{-/}}$ mice to be lighter than their wild-type (WT) littermates, and as such our central hypothesis was that LR11 was in some manner acting as a negative regulator of metabolism. To formally assess differences in body weight, WT and $\operatorname{Lr} 11^{-/-}$mice were fed standard chow or HFD to maximally expose differences in weight gain. The body weight of WT 8-weeks-old mice on chow diet was similar to those of $\operatorname{Lrl1}^{-/-}$mice; however, the size of the retroperitoneal and reproductive fat pads were significantly reduced (Table 1). In contrast, HFD-fed $\mathrm{Lr}_{1} 1^{-/-}$mice had markedly lower body weights than WT controls, a large portion of which was accounted for by reductions in the weights of WAT and liver (Table 1 and Supplementary Table 1). Reduced adiposity after 8 weeks of HFD was clearly evident from anatomical examinations (Fig. 1a-f) and histological analyses revealed that $\mathrm{Lr}_{1} 1^{-/-}$mice had smaller lipid droplets in BAT (Fig. 1e) and were protected from hepatic steatosis (Fig. 1f). Analysis of weekly energy balance on chow diet confirmed no significant difference in rate of body weight change or daily food intake in 10-11-week-old mice (Fig. 1g-i). Longer term monitoring of weight change in a separate study indicated a clear increase in weight gain in WT mice fed a HFD, with a high rate of divergence from the persistently lean $\mathrm{Lr} 11^{-/-}$mice observed by the comparative 10-weeks-old time-point (Fig. 2a). Averaged daily food intakes over the course of this study again confirmed no difference between genotypes $(\mathrm{WT}=59.9 \pm 1.1$, $\left.\operatorname{Lr} 11^{-/-}=60.5 \pm 1.2 \mathrm{~kJ} \mathrm{day}^{-1}\right) \quad$ or HFD $\quad(\mathrm{WT}=70.1 \pm 3.8$, $\left.\operatorname{Lr} 11^{-/-}=70.1 \pm 2.9 \mathrm{~kJ} \mathrm{day}^{-1}\right)$. We hypothesized that increased energy expenditure was facilitating the reduction in the rate of weight gain in $L r 11^{-/-}$mice fed HFD. Assessment of energy expenditure using indirect calorimetry confirmed that Lr11 ${ }^{-1-}$ mice had a higher metabolic rate than WT mice when fed HFD $\left(30 \pm 0.4\right.$ vs $27.5 \pm 0.3 \mathrm{~J} \mathrm{~min}^{-1}$ ) (Fig. $\left.2 \mathrm{~b}, \mathrm{c}\right) . \operatorname{Lr}_{1}{ }^{-/-}$ mice also displayed improved serum biochemistry profiles, with lower fasting glucose, insulin and triglyceride levels, particularly on HFD (Fig. 2d-f). Other circulating factors such as free-fatty acids, T4, leptin and serum cholesterol were not significantly altered (Fig. 2g-k), nor were any significant alterations in LPL activity observed in $\operatorname{Lr1} 1^{-/-}$tissues (Fig. 2l).

Lr11 ${ }^{-/-}$mice have increased thermogenic markers in WAT. LR11 is known to have a predominantly neuronal expression profile $^{17}$. However, analysis of Lr11 mRNA expression in WT adipose tissue revealed similar levels to those found in brain, with real-time quantitative PCR ct values of $26.9 \pm 4.1$ in brain versus $26.6 \pm 0.6$ in BAT and $28.7 \pm 0.8$ in subcutaneous WAT (scWAT) $(n=8)$. We therefore examined whether phenotypic changes in

\begin{tabular}{|c|c|c|c|c|c|c|c|}
\hline & Body (g) & $\begin{array}{c}\text { Reproductive } \\
\text { fat pad (g) }\end{array}$ & $\begin{array}{c}\text { Inguinal } \\
\text { fat pad (g) }\end{array}$ & $\begin{array}{c}\text { Retroperitoneal } \\
\text { fat pad (g) }\end{array}$ & Heart (g) & Liver (g) & Kidney (g) \\
\hline WT & $23.8 \pm 1.9$ & $0.37 \pm 0.05$ & $0.29 \pm 0.03$ & $0.12 \pm 0.01$ & $0.13 \pm 0.01$ & $1.14 \pm 0.19$ & $0.29 \pm 0.03$ \\
\hline Lr11-/ - & $21.56 \pm 1.34$ & $0.24 \pm 0.02$ & $0.27 \pm 0.04$ & $0.05 \pm 0.01$ & $0.13 \pm 0.01$ & $1.23 \pm 0.07$ & $0.31 \pm 0.06$ \\
\hline$\%$ of wild type & 91 & 64 & 94 & 38 & 100 & 108 & 106 \\
\hline WT & $34.13 \pm 4.53$ & $2.19 \pm 0.45$ & $1.77 \pm 0.26$ & $0.81 \pm 0.15$ & $0.13 \pm 0.01$ & $1.43 \pm 0.17$ & $0.33 \pm 0.02$ \\
\hline LR11 - / - & $23.63 \pm 4.21$ & $0.95 \pm 0.46$ & $0.84 \pm 0.36$ & $0.24 \pm 0.12$ & $0.13 \pm 0.01$ & $0.92 \pm 0.25$ & $0.32 \pm 0.01$ \\
\hline$\%$ of WT & 69 & 43 & 47 & 30 & 100 & 64 & 96 \\
\hline
\end{tabular}


a

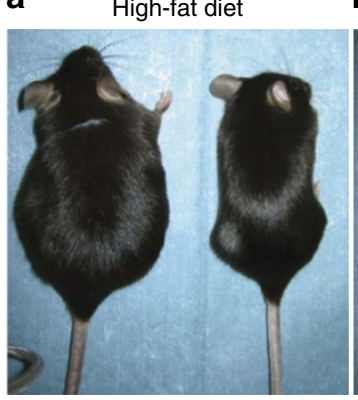

WT

d

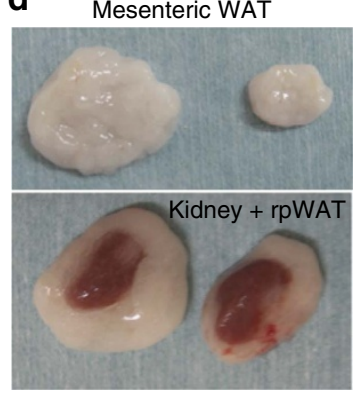

WT b

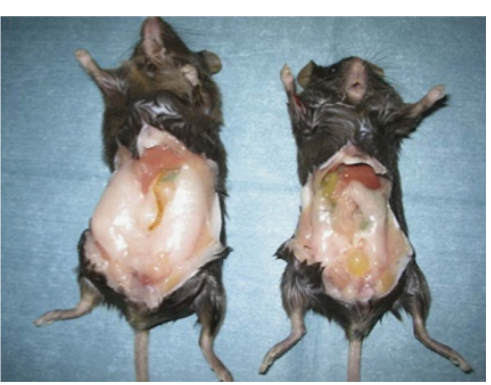

WT

e
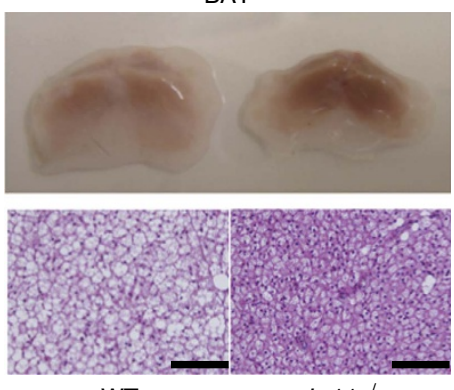

WT

h

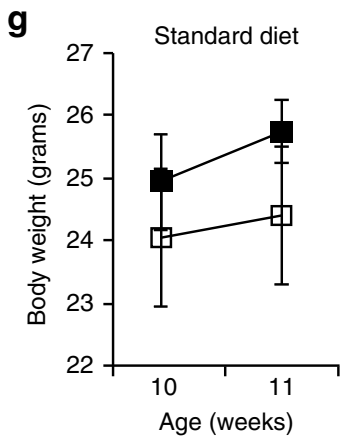

C Epididymal WAT

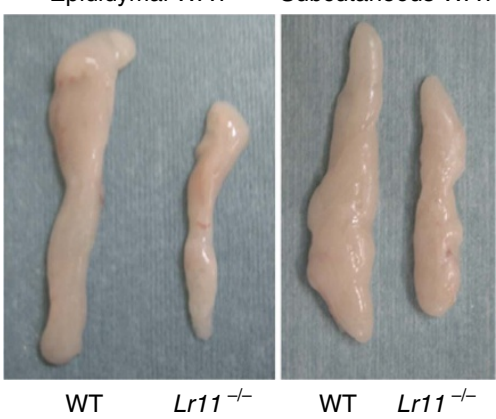

f
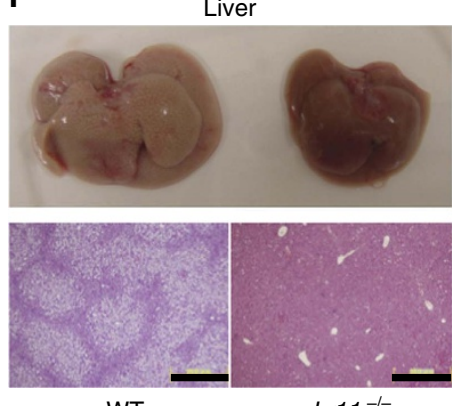

WT

i

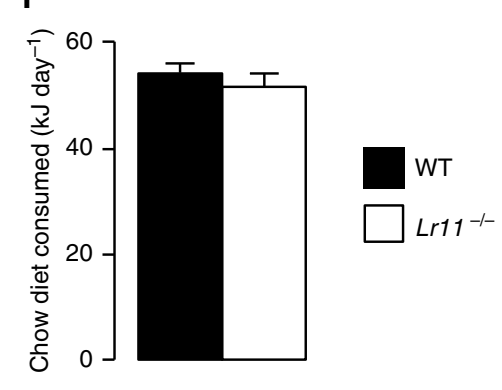

Figure 1 | $\mathbf{L r 1 1}{ }^{-/-}$mice display reduced adiposity when fed a HFD. (a) Representative images of body size, (b) intra-abdominal fat, (c,d) separate white adipose depots and (e) brown adipose tissue and (f) livers with haematoxylin and eosin staining of histological sections from mice fed HFD from 8 to 16 weeks of age; scale bars, $200 \mu \mathrm{m}$. (g) Body weight, (h) change in body weight and (i) energy consumed in WT and Lr11 ${ }^{-/-}$mice over the course of 1 week being fed standard chow while single housed, $n=5$, data represented as means \pm s.e.m. (see also Table 1 and Supplementary Table 1).

adipose tissue may be driving the metabolic shift observed in Lr11 ${ }^{-/}$mice. Reduced lipid content in $\operatorname{Lr} 11^{-/}$BAT on HFD (Fig. 1e) suggested that the tissue was more metabolically, and thus thermogenically, active. Examination of scWAT revealed smaller, less lipid replete adipocytes (Fig. 3a), suggesting either reduced lipid storage or increased lipid oxidation. Previous studies have shown that scWAT has a high propensity for 'browning' in response to pharmacological and nutritional signals ${ }^{18}$. Therefore, we performed immunostaining, which confirmed significantly higher levels of uncoupling protein 1 (UCP1) than in WT tissue (Fig. 3b). Microarray analysis of gene expression revealed significant increases in thermogenic genes, particularly in $\mathrm{LrI1}^{-\mathrm{O}-}$ versus WT scWAT (Supplementary Table 2). Based on histological and microarray data we hypothesized that increased thermogenesis in adipose tissue could explain the increase in metabolic rate in $\operatorname{Lr} 11^{-/-}$mice. Increased expression of known key thermogenic factors was confirmed using quantitative PCR with reverse transcription, including BMP $8 \mathrm{~b}(B m p 8 b)$, which we have previously shown to be an important regulator of diet-induced thermogenesis (Fig. 3c) ${ }^{3}$. Similar gene expression changes were observed in canonical BAT, albeit to a lesser extent (Fig. 3d), likely because of the already high levels of thermogenic gene expression making detection of further modest increases more difficult. Other VPS10p or low-density lipoprotein receptor gene family receptors such as Sortilin 1 (Sort1) and low-density lipoprotein receptor related protein 1 ( Lrp1) did not display any significant compensatory regulation in either scWAT or BAT (Fig. 3c,d). No changes to markers of vascular endothelial cells or the smooth muscle cell marker, alpha actin 2 (Acta2), were detected in either BAT or subcutaneous WAT of $\mathrm{Lr}^{-/-}$ mice (Fig. 3e,f).

Lr11 ${ }^{-/-}$mice are more thermogenic following high-fat diet. Increased thermogenic gene expression in $\mathrm{LrI1}^{-9}$ mice fed an HFD, coupled with the reduced body weight suggested that Lr11 ${ }^{-/-}$mice may have increased diet-induced thermogenesis. To functionally address changes in thermogenic capacity in response to increased energy availability, we assessed the thermogenic capacity of $\mathrm{Lr}_{1} 1^{-}$- mice in response to HFD. To eliminate any effect of environmental temperature, mice were 
a

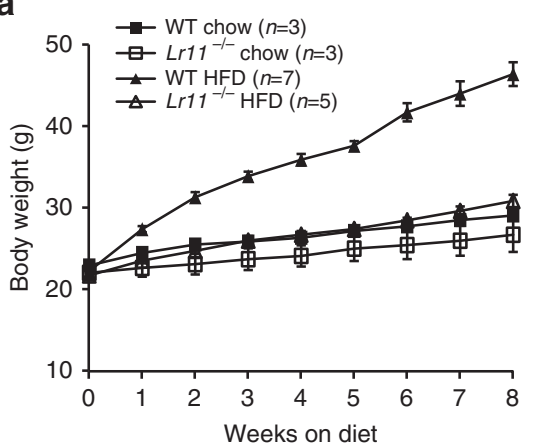

b

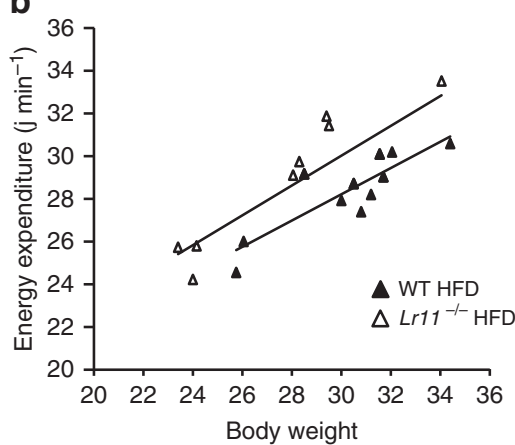

c

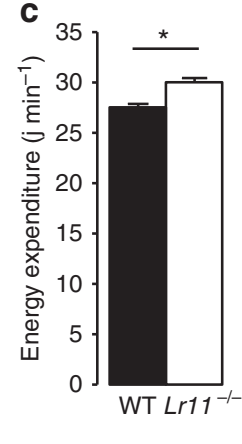

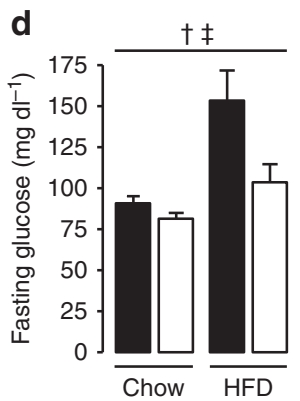
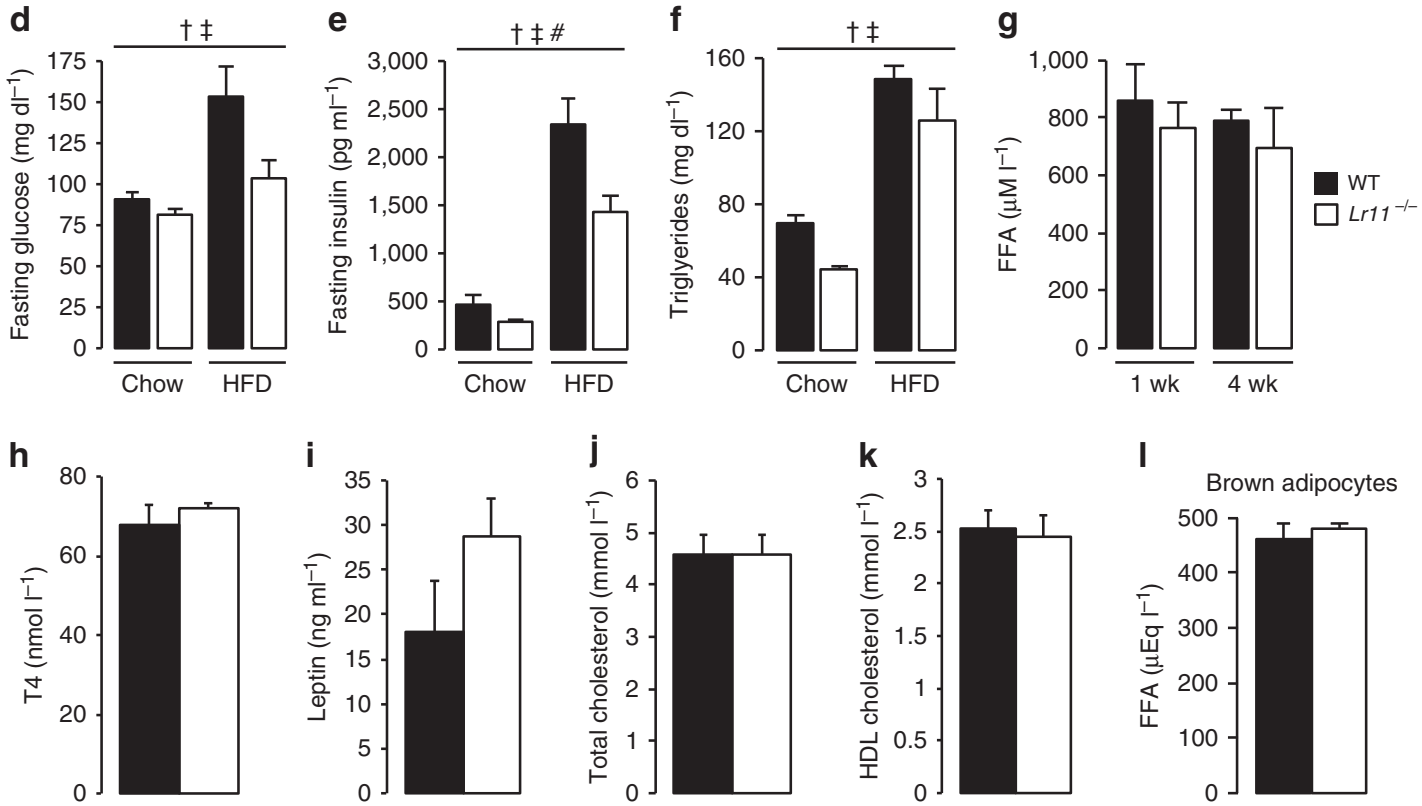

Figure 2 | Lr11 ${ }^{-/-}$mice are hypermetabolic with improved serum biochemistry. (a) Growth curves of wild-type and $L r 11^{-/-}$mice fed chow and HFD from 8 to 16 weeks. (b) Indirect calorimetry expressed as a scatter plot showing the correlation between energy expenditure and body weight for singlehoused, 12-week-old wild-type $\left(R^{2}=0.75\right)$ and $L r 11^{-/-}\left(R^{2}=0.74\right)$ mice fed HFD (60\% fat) from 8 to 16 weeks; and in (c) also expressed as an adjusted mean energy expenditure for an adjusted mean body weight of $29.29 \mathrm{~g}$, P-value obtained using analysis of covariance, $n=8-11$. (d) Fasting glucose,

(e) fasting insulin, (f) fasting serum triglycerides following 8 weeks of diet administration from 8-16 weeks old. (g) Fasting free-fatty acids following 1 and 4 weeks of HFD from 8-weeks-old mice and (h-k) serum measurements of hormones and lipids in 16-week-old male wild-type and Lr11 -/- mice fed HFD from 8 to 16 weeks, $n=5-6$. (I) Lipoprotein lipase activity in conditioned media from mature adipocyte cultures from murine BAT of WTand Lr11 ${ }^{-/-}$mice, using free-fatty acid production as a readout $(n=3-4)$. Data are presented as means \pm s.e.m. $\dagger, \ddagger$ and \# denote significant effect of genotype, diet and genotype*diet interaction respectively, obtained using 2-way ANOVA. (See also Supplementary Table 2). FFA, free-fatty acid.

housed at thermoneutrality $\left(30^{\circ} \mathrm{C}\right)$ while being fed HFD for 8 weeks before measurement. In this setting, any alterations to maximum thermogenic capacity are driven by diet alone and dependent on functional BAT, as demonstrated previously using mice lacking Ucp1 (ref. 19). $\mathrm{Lr}_{1}{ }^{-/}$mice showed a greater increase in energy expenditure from baseline in response to norepinephrine (NE) injection compared with WT littermates, corresponding to $\sim 12 \mathrm{~J} \mathrm{~min}^{-1}$ (Fig. $4 \mathrm{a}, \mathrm{b}$ ). This demonstrated that HFD-fed $\mathrm{Lr}_{11}{ }^{-/-}$mice had increased BAT recruitment and thermogenic adaptation to HFD.

sLR11 inhibits $\mathrm{O}_{2}$ consumption in brown adipocytes. Based on the thermoneutral HFD study data we hypothesized that a lack of LR11 allowed animals to mount a disproportionately high thermogenic response to increased sympathetic nervous system stimulation following an increase in caloric intake. Primary brown adipocytes (which normally have high endogenous thermogenic capacity) from WT and $\mathrm{LrI1}^{-/-}$mice were cultured and differentiated in the presence or absence of purified sLR11 (ref. 20). Functional thermogenic capacity was assessed by NE-induced cellular respiration, as NE is the major signal from the sympathetic nervous system that stimulates thermogenesis in brown adipocytes ${ }^{21}$. Differentiated WT and KO adipocytes showed similar basal respiration levels but primary adipocytes from BAT of $L r 11^{-/-}$mice showed a greater response to NE stimulation compared with cells from WT mice (Fig. 4c). Conversely, treatment of $\mathrm{Lr}_{1}{ }^{-/-}$cells with sLR11 almost completely ablated the enhanced effect of NE stimulation on oxygen consumption (Fig. 4d) and sLR11 significantly reduced lipolysis in WT brown adipocytes, as indicated by glycerol release in response to maximum stimulation with NE (Fig. 4e). Opposite to tissues lacking LR11, sLR11 treatment of WT primary brown adipocytes resulted in a significant reduction in expression of multiple genes essential for thermogenesis, including $U c p 1, P g c 1 \beta$ and $\beta 3$ adrenergic receptor (Adr $\beta 3$ ) (Fig. 4f). 
a

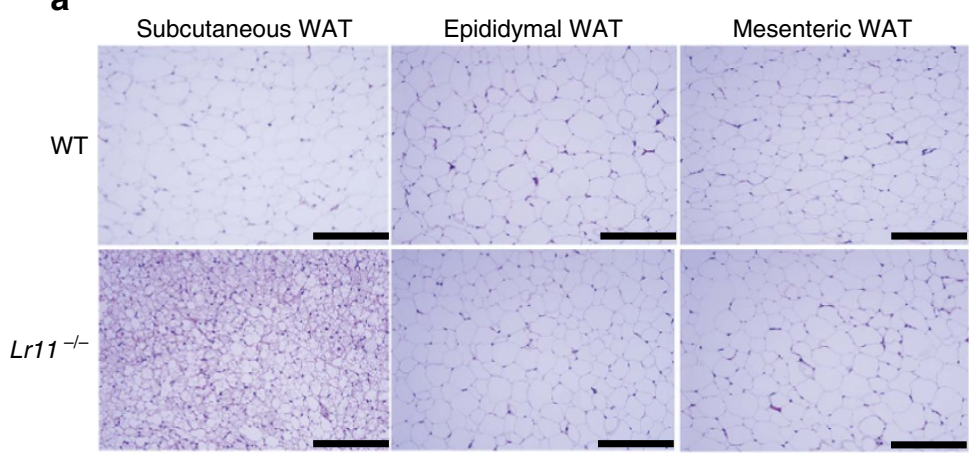

b

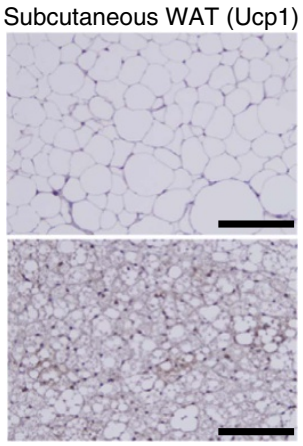

C

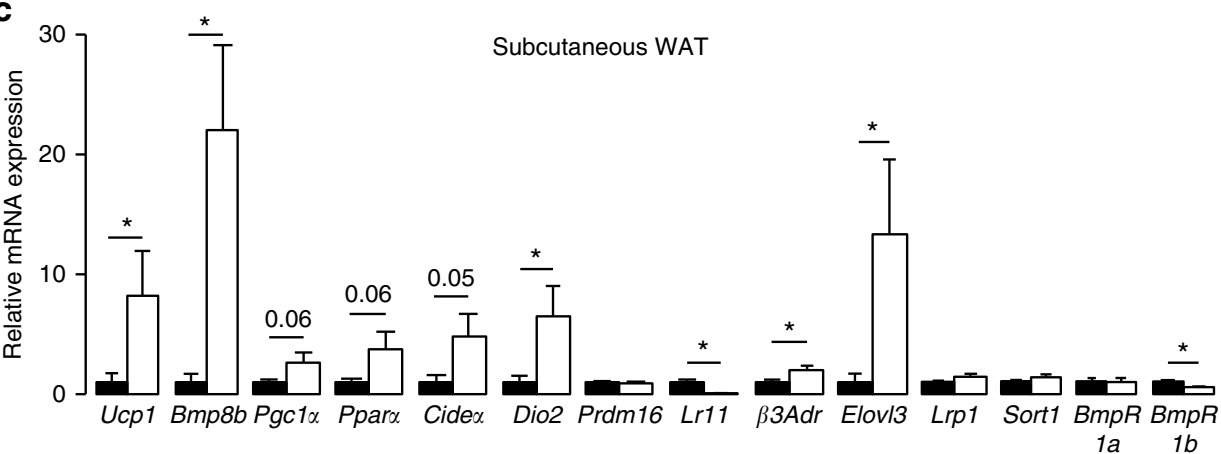

d

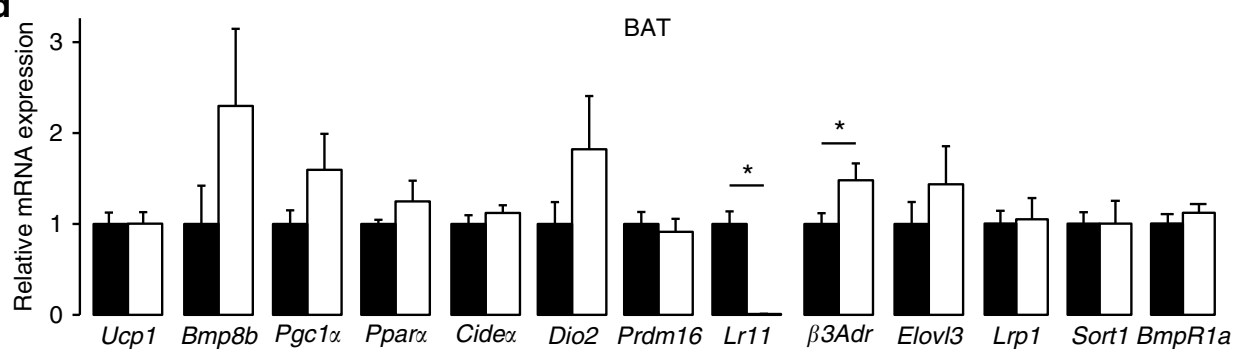

e

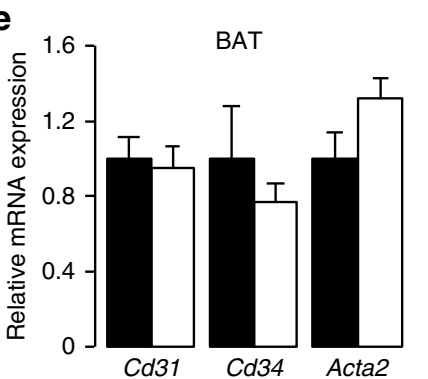

f

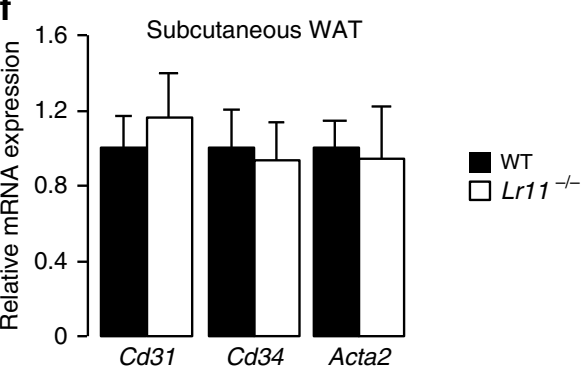

Figure 3 | Lr11 - /- mice exhibit increased browning of adipose tissue. (a) Representative haematoxylin and eosin stained sections from WAT depots in 16-week-old wild-type and Lr11-/- mice fed HFD from 8-16 weeks; scale bars, $200 \mu \mathrm{m}$. (b) UCP1 staining and (c) metabolic gene expression in subcutaneous WAT and (d) BAT and (e) Vascular and smooth muscle cell marker gene expression in BAT and (f) subcutaneous WAT of the same animals, $n=7-8)$. Data are presented as means \pm s.e.m, ${ }^{\star}=P<0.05$ obtained using one-way ANOVA followed by Tukey post-hoc test.

sLR11 inhibits thermogenesis via the BMP/Smad pathway. Bmp7 and its downstream signalling cascade, which requires phosphorylation of Smad proteins, has been identified as a key mechanism regulating the formation of BAT and recruitment of 'beige' adipocytes within $\mathrm{WAT}^{22-25}$. To examine whether LR11 was interacting with this mechanism to regulate the observed browning of scWAT, we differentiated primary adipocytes from scWAT of WT and $\mathrm{LrI1}^{-/-}$mice in the presence of recombinant BMP7. BMP7 is a known driver of thermogenic development and, as a member of the TGF $\beta$ superfamily, signals through BMP receptors (BMPR) to increase phosphorylation of intracellular Smad proteins ${ }^{25}$. Cells lacking LR11 displayed a significantly greater increase in thermogenic gene expression in response to BMP7, and this response was completely blocked in cells of both genotypes by treatment with sLR11 (Fig. 5a-c). Phosphorylation of Smads 1, 5 and 8 following BMP7 treatment of primary adipocytes was also greatly reduced by sLR11 co-treatment (Fig. 5d). sLR11 treatment was also blocked downregulation of the BMP receptor Bmpr1b, observed after BMP7 treatment (Fig. 5e,f) and significantly reduced phosphorylation of SMAD3 in adipocytes following stimulation with TGF $\beta$ (Fig. 5g). Further evidence for the ability of sLR11 to 
a

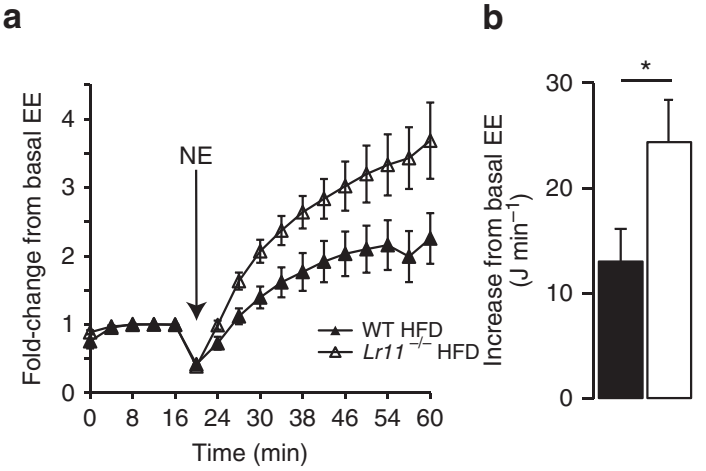

C Brown adipocytes

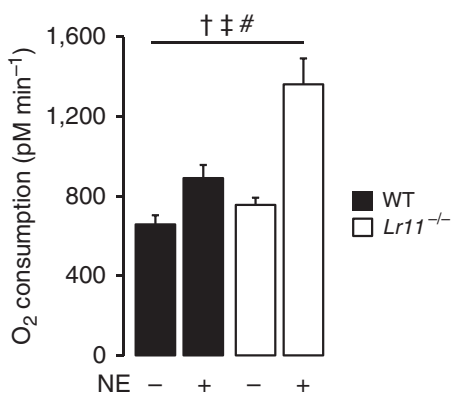

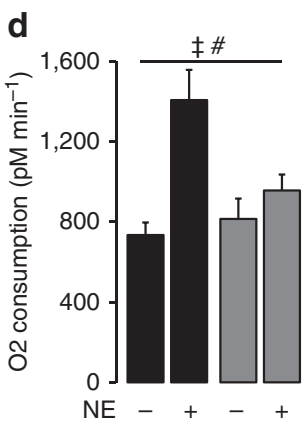

Wild-type brown adipocytes

e

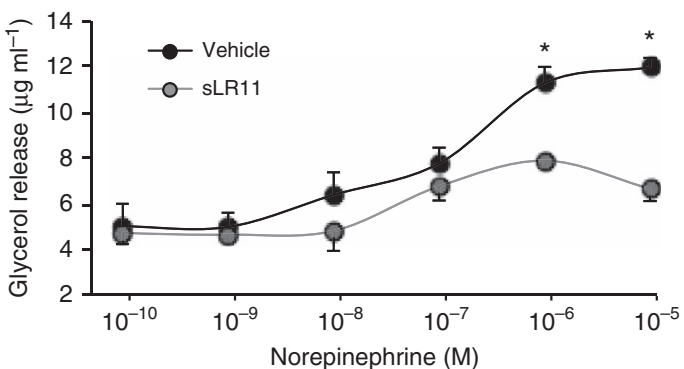

f

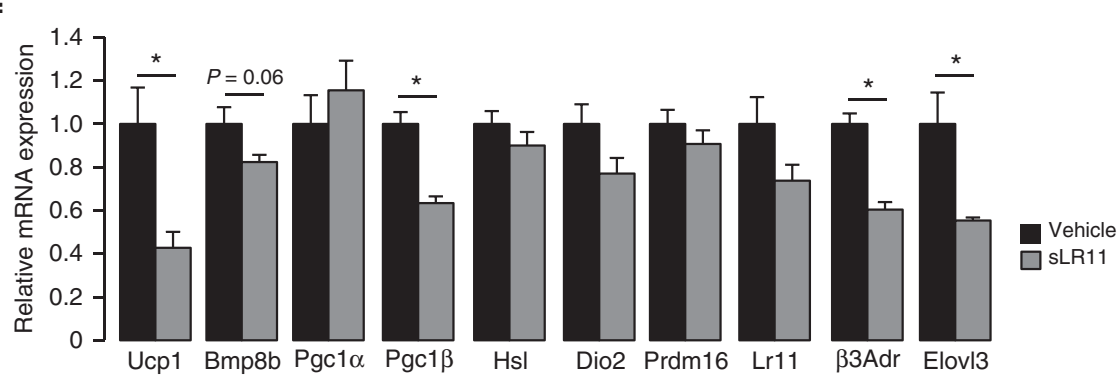

Figure 4 | Soluble LR11 inhibits metabolism by inhibiting thermogenesis in brown adipocytes. (a) NE-induced increase in energy expenditure in anaesthetised mice fed 60\% high-fat diet and housed at thermoneutrality for 8 weeks, expressed as fold-change from baseline and (b) measured increase from baseline. Arrow indicates norepinephrine injection time, $n=6$ or 7 . (c) Cellular respiration in differentiated primary adipocytes from BAT of wild-type and $L r 11^{-/-}$mice in response to $100 \mathrm{nM} \mathrm{NE}, n=9-10$. (d) Cellular respiration in primary adipocytes from wild-type BAT treated with vehicle or $10 \mathrm{ng} \mathrm{ml}^{-1}$ of soluble LR11, $n=9$ or 10. (e) Lipolysis measured by glycerol release from differentiated brown adipocytes in response to increasing concentrations of norepinephrine $+/-10 \mathrm{ng} \mathrm{ml}^{-1}$ of $\operatorname{sLR} 11$ over $2 \mathrm{~h}, n=4$. (f) Thermogenic gene expression in wild-type primary brown adipocytes, differentiated in the presence of vehicle or $100 \mathrm{ng} \mathrm{ml}^{-1}$ soluble $\operatorname{Lr} 11$ ( $n=4$ triplicate experiments). Data presented as mean \pm s.e.m., ${ }^{*}=P<0.05$ using oneway ANOVA followed by Tukey post-hoc test where appropriate. $\dagger, \ddagger$ and \# denote a significant effect of genotype, treatment and genotype treatment interaction respectively, using 2-way ANOVA, for (d) $\dagger=$ effect of sLR11 treatment, $\ddagger=$ effect of NE treatment and \#= treatment interaction.

directly inhibit the BMP signalling pathway was provided by an immunoprecipitation assay, which showed that sLR11 was able to bind BMPR1a and BMPR1b, but not BMPR2 (Fig. 5h). Finally, reduced expression of either BMPR1a or BMPR1b in cultured brown adipocytes was sufficient to negate the repressive action of sLR11 on Ucp1 expression (Fig. 5i).

The cytoplasmic domain of LR11 has also been shown to function as a transcription factor ${ }^{26}$, leading us to test whether LR11 could regulate the transcriptional activity of known thermogenic response elements. Overexpression of LR11 resulted in a small but significant reduction in transcription driven by the $B m p 8 b$ promoter, a thyroid response element and the Ucp1 promoter enhancer, but not by the Ucp 1 core promoter (Supplementary Fig. 1). We next examined the physiological regulation of LR11 and found its gene expression to be regulated in line with thermogenic activation, decreasing in both BAT and scWAT as environmental temperature rose from cold to thermoneutrality (Fig. 6a). Serum sLR11 levels followed the same pattern, reaching their highest point at $5^{\circ} \mathrm{C}$ when thermogenesis is maximally activated in mice (Fig. 6b). Lr11 mRNA was also regulated by changes to energy availability in a pattern identical to thermogenesis, increasing in the fed state and declining after fasting (Fig. 6c).

sLR11 levels correlate with BMI and adiposity in humans. Finally, to test the relevance of our findings to human metabolism and as LR11 is highly expressed in adipose tissue, we examined the relationship between adiposity and sLR11 in two cohorts of patients. In 156 subjects with sleep apnoea (Supplementary Table 4), circulating sLR11 levels were positively correlated with age, BMI, visceral (VFA) and subcutaneous fat areas (SFA), and HbAlc and negatively correlated with smoking and high-density lipoprotein (HDL) cholesterol (Fig. 6d-f and Table 2). Multiple 
a

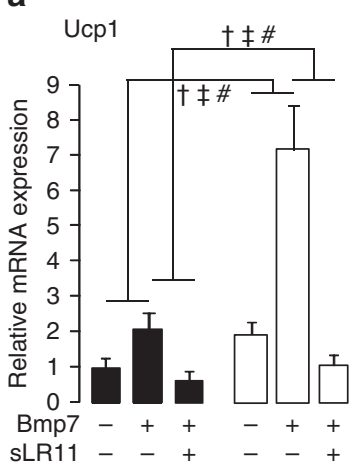

b

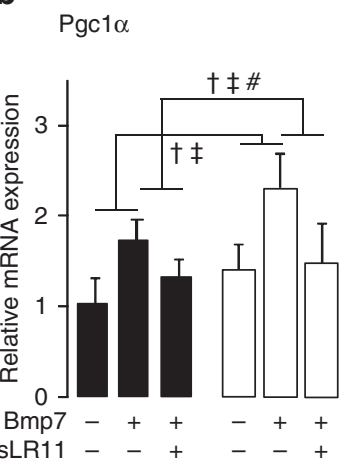

d
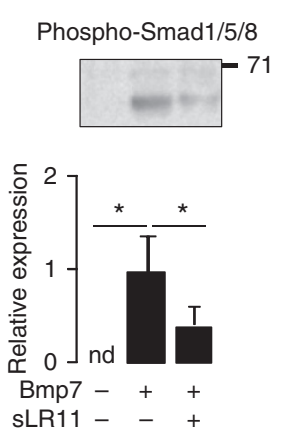

g

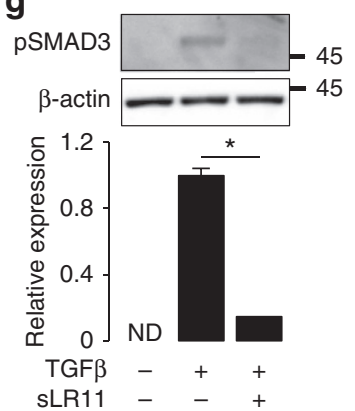

e Bmpr1a

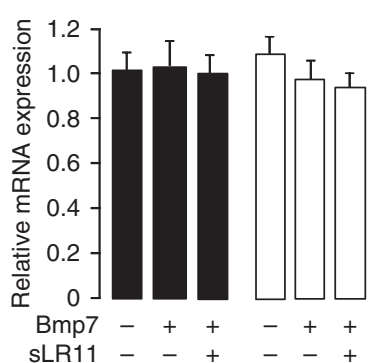

h

IP Ab

Blot Ab IgG control Anti-LR11

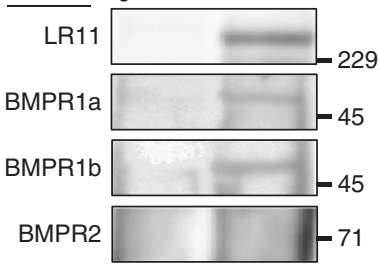

C

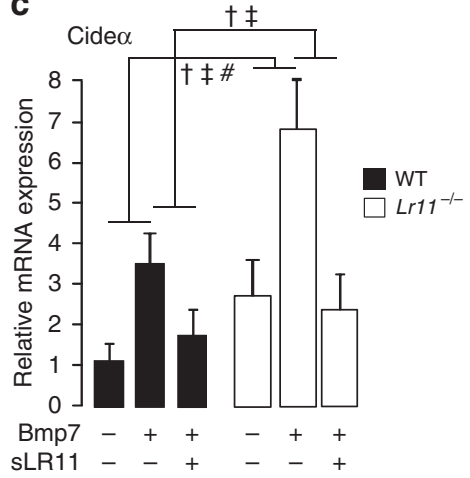

f Bmpr1b

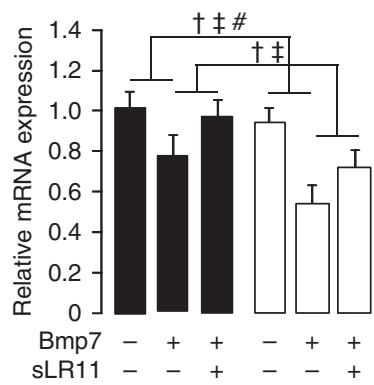

i

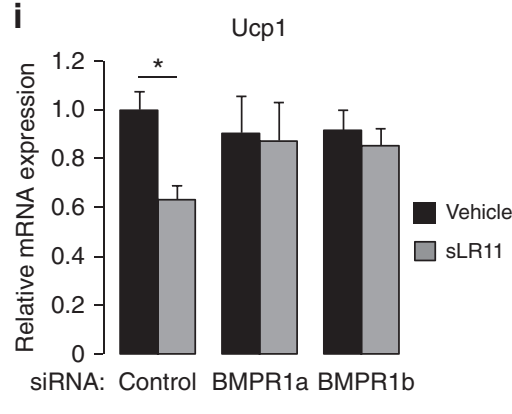

Figure 5 | Soluble LR11 inhibits thermogenesis by inhibiting BMP signalling. (a-c and $\mathbf{e , f}$ ) Gene expression in differentiated primary adipocytes from subcutaneous WAT of wild-type and $L \mathrm{r} 11^{-/}$- mice incubated with $3.3 \mathrm{nM} \mathrm{BMP7}$ for the first 2 days and $10 \mathrm{ng} \mathrm{ml} \mathrm{I}^{-1} \mathrm{sLR} 11$ throughout the incubation $(n=6)$. (d) Levels of phosphorylated Smad proteins $15 \mathrm{~min}$ after treatment with vehicle or $3.3 \mathrm{nM}$ BMP7 in primary adipocytes subcutaneous WAT of wild-type mice, differentiated $-/+10 \mathrm{ng} \mathrm{ml}^{-1} \mathrm{sLR} 11(n=6)$. (g) Western blot for phospho-Smad3 in mature adipocytes cultured from subcutaneous WAT of wild-type mice treated for 30 min with $2 \mathrm{ng} \mathrm{ml}^{-1} \mathrm{TGF} \beta$ in the presence or absence of $10 \mathrm{ng} \mathrm{ml}^{-1} \mathrm{sLR} 11$. (h) Western blot showing denoted proteins immunoprecipitated from membrane protein extracts from differentiated human adipocytes from scWAT with an antibody to LR11. (i) Ucp1 mRNA expression following $2 \mathrm{~h}$ stimulation with $10 \mathrm{ng} \mathrm{ml}^{-1} \mathrm{sLR} 11$ in mature adipocytes cultured from wild-type BAT and transfected with the indicated siRNA for BMP receptors. Data presented as mean \pm s.e.m., ${ }^{\star}=P<0.05$ using one-way ANOVA followed by Tukey post-hoc test. $\dagger$, $\ddagger$ and \# denote a significant of genotype, treatment and genotype ${ }^{\star}$ treatment interaction respectively, using 2-way ANOVA. Blot protein weights shown in kDa. (see also Supplementary Fig. 2).

regression analysis of these variables showed that sLR11 levels were not significantly associated with any of them but tended to associate most with VFA, independently of other factors (Table 2). A second study of 25 patients with type 2 diabetes mellitus or glucose intolerance-associated metabolic disorders (Supplementary Table 5) showed a similar significant correlation between BMI and sLR11 levels (Fig. $6 \mathrm{~g}$ ). Importantly none of the other measured characteristics of these subjects, such as age, HbA1c or cholesterol levels, showed any correlation with sLR11 (Supplementary Table 5). This further suggested that overall body weight, and thus adiposity, was the major determinant of sLR11 levels in humans. In a third study of 14 obese patients who underwent bariatric surgery, post-operative sLR11 levels were significantly reduced after 12 months, concomitantly with reductions to BMI, VFA and SFA (Table 3). The percentage reduction in sLR11 was positively correlated with that of VFA and SFA (Fig. 6h,i). Multiple regression analysis of the two significant correlates, VFA and SFA, showed no significance between their respective contributions to the relationship (Table 3), suggesting that overall fat mass, regardless of its distribution, was driving the correlation.

\section{Discussion}

Our data demonstrate a role for sLR11 as a negative regulator of thermogenesis, acting through the BMP/Smad pathway in adipose tissue to suppress activation of thermogenic machinery and inhibit transcription of key thermogenic genes. LR11 is 
a

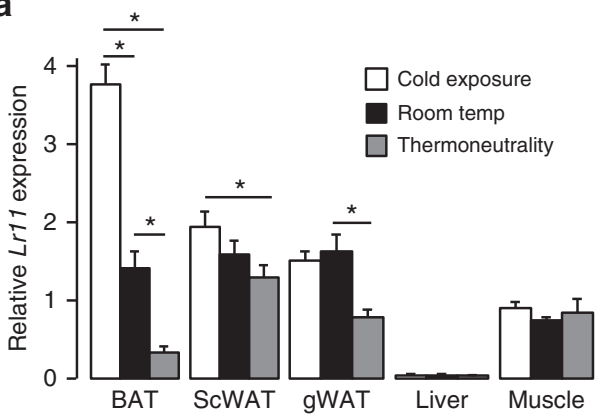

b

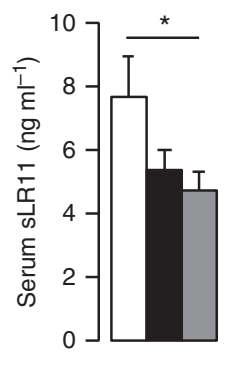

C

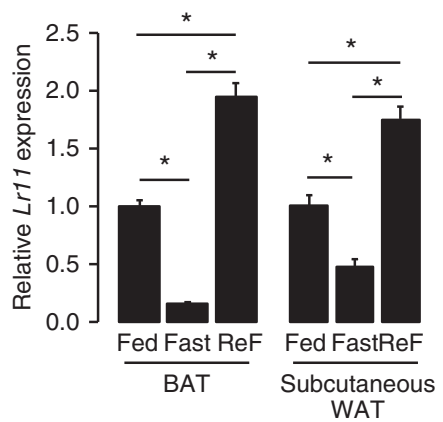

Study 1: sleep apnoea patients

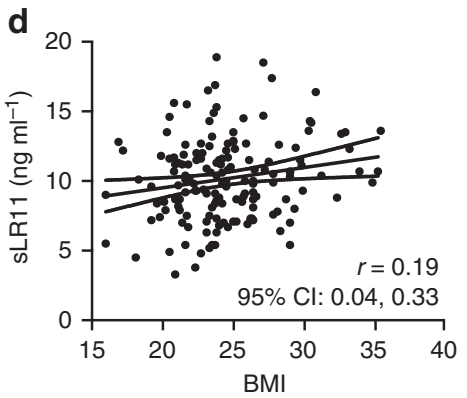

e
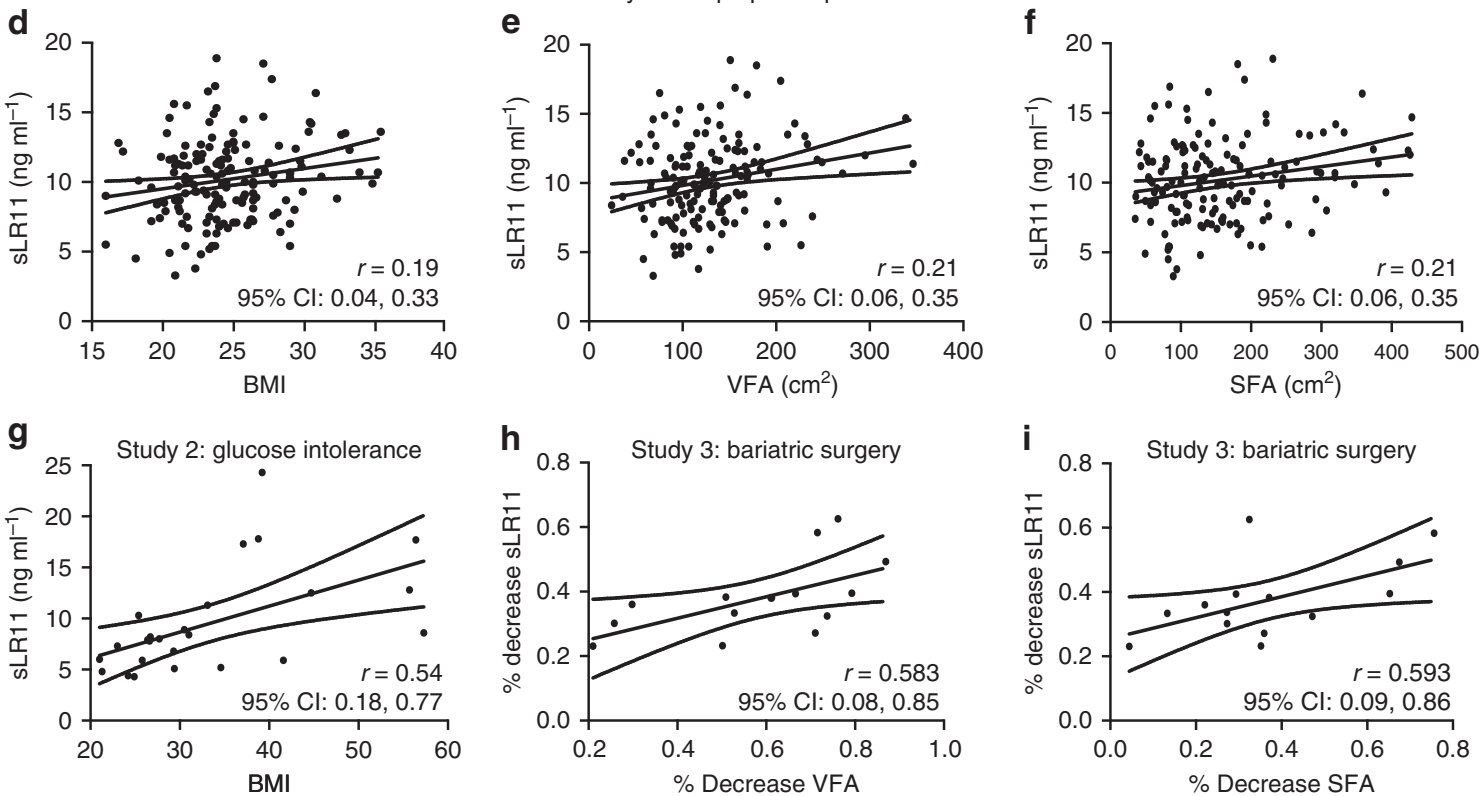

Figure 6 | sLR11 levels are metabolically regulated and correlate with BMI and adiposity in humans. (a) Lr11 mRNA expression levels in tissues from 12 week-old mice exposed to cold $\left(5^{\circ} \mathrm{C}\right)$, room temperature $\left(23^{\circ} \mathrm{C}\right)$ or thermoneutrality $\left(30^{\circ} \mathrm{C}\right)$ for 3 weeks $(n=8)$ and $(\mathbf{b})$ serum sLR11 levels in mice housed under the same conditions $(n=4)$. (c) Lr11 mRNA expression in BAT and ScWAT from fed, $24 \mathrm{hr}$ fasted and $24 \mathrm{~h}$ re-fed mice $(n=8)$, data presented as mean \pm s.e.m., ${ }^{*}=P<0.05$ using one-way ANOVA followed by Tukey post-hoc test. (d) Serum sLR11 levels in patients with sleep apnoea correlated with BMI, (e) VFA and (f) SFA $(n=156)$. (g) Serum sLR11 levels in patients with type 2 diabetes mellitus or glucose intolerance-associated metabolic disorders correlated with BMI, $(n=25)$. (h) \% reduction in serum sLR11 levels in 14 obese patients 12 months after bariatric surgery correlated with \% reduction to VFA and (i) SFA. Correlations evaluated using Pearson correlation (see also Tables 2 and 3). scWAT, subcutaneous white adipose tissue; gWAT, gonadal adipose tissue.

Table 2 | Correlation between sLr11 levels and characteristics of sleep apnoea.

\section{Single correlation with sLR11 levels}

Factors

Age

Total cholesterol

Triglyceride

HDL-cholesterol

LDL-cholesterol

BMI

VFA

SFA

HbA1c

CAD, yes/no

CVD, yes/no

Sex, men/women

Smoking, yes/no

renth

(2)

r or mean \pm s.d.

\subsection{9}

0.039

0.062

$-0.196$

0.108

0.186

0.212

0.206

0.171

$9.72 \pm 2.91 / 10.43 \pm 2.98$

$10.00 \pm 2.19 / 10.19 \pm 3.01$

$10.08 \pm 2.91 / 10.39 \pm 3.10$

$9.66 \pm 2.83 / 10.79 \pm 3.02$
Multivariate analysis of correlates

\begin{tabular}{lcl}
\multicolumn{1}{c}{$\boldsymbol{P}$} & $\boldsymbol{\beta}$ & $\boldsymbol{P}$ \\
\cline { 2 - 3 } $\mathbf{0 . 0 3 5}$ & 0.034 & 0.084 \\
0.626 & & \\
0.443 & -0.008 & 0.541 \\
$\mathbf{0 . 0 1 4}$ & & \\
0.18 & 0.047 & 0.548 \\
$\mathbf{0 . 0 2}$ & 0.008 & 0.056 \\
$\mathbf{0 . 0 0 8}$ & 0.001 & 0.83 \\
$\mathbf{0 . 0 1}$ & 0.080 & 0.736 \\
$\mathbf{0 . 0 3 2}$ & & \\
0.175 & & \\
0.962 & & 0.19 \\
0.489 & -0.482 &
\end{tabular}

BMI, body mass index; CAD, coronary artery disease; CVD, cerebrovascular disease; HDL, high-density lipoprotein; LDL, low-density lipoprotein; SFA, subcutaneous fat areas; VFA, visceral fat areas. Initial correlations derived using Pearson correlation test. Multiple regression analysis performed in patients to examine the seven characteristics more strongly correlated with sLR11 levels using beta weights to detect significant differences in the contribution of each factor, $n=156$. 
Table 3 | Effect of bariatric surgery on adiposity and sLR11.

Characterization pre- and 12 month post-bariatric surgery $(n=14)$

\begin{tabular}{lcccc}
\hline Factor & Before & After & P & \% reduction \\
\hline SLR11 & $16.79 \pm 7.03 \mathrm{ng} \mathrm{ml}^{-1}$ & $10.36 \pm 4.84 \mathrm{ng} \mathrm{ml}^{-1}$ & $\mathbf{0 . 0 0 1}$ & $37.6 \pm 11.9$ \\
BMI & $44.37 \pm 8.64$ & $31.43 \pm 5.41$ & $\mathbf{0 . 0 0 1}$ & $28.3 \pm 9.7$ \\
VFA & $245.30 \pm 135.44 \mathrm{~cm}^{2}$ & $96.84 \pm 57.44 \mathrm{~cm}^{2}$ & $\mathbf{0 . 0 0 1}$ & $57.7 \pm 20.9$ \\
SFA & $651.23 \pm 439.63 \mathrm{~cm}^{2}$ & $356.50 \pm 129.76 \mathrm{~cm}^{2}$ & $\mathbf{0 . 0 0 1}$
\end{tabular}

Correlation with \% reduction in SLR11

\begin{tabular}{|c|c|c|c|c|c|c|}
\hline & & & & & & \\
\hline & & & & & & \\
\hline & $r$ & Lower & Upper & B & Lower & Upper \\
\hline$\%$ reduction of $\mathrm{BMI}$ & 0.422 & -0.140 & 0.778 & & & \\
\hline$\%$ reduction of VFA & 0.583 & 0.076 & 0.851 & 0.211 & -0.236 & 0.659 \\
\hline$\%$ reduction of SFA & 0.561 & 0.043 & 0.841 & 0.165 & -0.292 & 0.622 \\
\hline
\end{tabular}

regulated in tissues with inherent/adaptive thermogenic capacity, in response to changes in environmental temperature and diet, but not in other metabolic tissues such as liver (Fig. 6a). In absence of any endogenous LR11, nutritional stimuli that induce thermogenesis in scWAT are left unchecked, leading to increased recruitment of brown adipocytes, reduced lipid accumulation, hypermetabolism and overall leanness.

Our in vitro data support a cell-autonomous role of sLR11 in regulating adipose tissue responses to increased energy availability. This is suggested by the peptide's ability to suppress the known thermogenic signalling pathways and the lack of any significant change to energy balance on a standard chow diet. Neurological roles for LR11 have been previously described, although we hypothesize that if LR11 is required to maintain a central circuit regulating metabolic rate, it would be expected that its ablation would yield a consistent phenotype across environmental conditions. Instead metabolic rate changes only become apparent in $\mathrm{LrI1}^{-/-}$mice fed HFD, when sympathetic tone to BAT and WAT depots increases and adaptive changes occur to strike a new balance between lipid oxidation and storage. In the absence of LR11 and thus sLR11, increased energy availability results in increased DIT in adipose tissue but without the appropriate anabolic response. Where WT mice are able to store additional calories as triglyceride, $\mathrm{Lr}_{1} 1^{-/}$mice can only increase the metabolic arm of the response and burn them. However, even on a chow diet there is a slight tendency for $\mathrm{Lr}_{11}{ }^{-/-}$mice to be lighter and consume slightly less food (Fig. 1g-i and Fig. 2a) and it is also highly likely that DIT is itself regulated by discrete neuronal pathways that mediate alterations to sympathetic activation of thermogenic tissues. Therefore we cannot rule out based on our current data, that LR11 may also play a central role in the initiation and maintenance of metabolic responses and energy balance.

LR11 has also been previously shown to increase vascular smooth muscle cell migration in response to injury ${ }^{11}$. We did not observe any alteration to vasculogenesis or angiogenesis in Lr11 ${ }^{-/-}$mice, suggesting that perturbations in these processes are not causative of the hypermetabolic phenotype. Similarly, the documented ability of LR11 to regulate LPL activity ${ }^{15}$ was not evident as a mechanism by which its deletion led to hypermetabolism in our model (Fig. 2l). Our data also suggest that sLR11 levels are dependent on adipose mass in humans, increasing in line with fat mass. Clinical interventions such as bariatric surgery that lead to reductions in adiposity, also lower sLR11 levels (Table 3 and Fig. 6h,i), potentially contributing to the observed increase in metabolic rate in such patients ${ }^{27,28}$. The fact that the strongest correlation in all human subjects is between sLR11 and visceral and SFA, rather than BMI is further evidence that adipose tissue is the main site of sLR11 production and secretion.

We identify LR11 as a key metabolic regulator, which functions to maintain the adequate balance between lipid storage and oxidation in response to changing environmental conditions and particularly when thermogenic activity is increased in capable tissues. This mechanism might be exploited for anti-obesity therapies or conversely, for the treatment of conditions such as anorexia nervosa or cachexia. The apparent anabolic role of sLR11 may also be relevant for understanding its prior implication in cardiovascular disease and Alzheimer's disease 29,30 . While an increasing number of factors and pharmacological molecules exist that either increase the number of brown adipocytes or their thermogenic capacity 9,31 , only a small number of negative regulators are apparent, namely nuclear receptor-interacting protein 140 (Rip140) and the diurnally regulated Rev-erb $\alpha$ (refs 32,33). It seems likely that other negative regulators must exist to ensure effective control of this energy-expensive mechanism and to 'fine tune' the thermogenic response. Before our study, a lipoprotein receptor-mediated mechanism for regulation of BMP signalling in the regulation of thermogenesis has not been described.

\section{Methods}

Animals and diets. Unless otherwise stated, all data are from work on males (8-16 weeks of age). C57Bl6/J mice were purchased from Charles River. $\mathrm{Lr}^{\mathrm{B}} 1^{-/}-$mice were generated as previously described ${ }^{11}$ on a C57Bl6/J background and compared to WT littermates. Unless stated, mice were housed in a temperature-controlled room $\left(22^{\circ} \mathrm{C}\right)$ with a 12 -h light/dark cycle with free access to diet and water. Standard chow or HFD was administered ad libitum from weaning until indicated. High-fat diet consisted of 60\% calories from fat (D12492, Research Diets, NJ, USA) unless otherwise stated. Thermoneutrality involved housing mice at $30^{\circ} \mathrm{C}$ in a normal home cage environment. All animal procedures were approved by either the UK Home Office or the Special Committee on Animal Welfare, School of Medicine, at the Inohana Campus of Chiba University.

Calculation of energy expenditure. Animals were placed in a monitoring system based on their home cages (Creative Scientific, Canterbury, UK) with the ability to measure oxygen and carbon dioxide concentrations using a system (Minimox) designed by Peter Murgatroyd (University of Cambridge) ${ }^{34}$. Oxygen consumption and carbon dioxide production was measured, with samples taken at $18 \mathrm{~min}$ intervals over a 48-h period. Energy expenditure was then calculated using indirect calorimetry with the Elia and Livesey constant ${ }^{35}$. Energy expenditure is expressed as $\mathrm{J} \mathrm{min}^{-1}$ per mouse using an adjusted mean body weight. This was obtained using analysis of covariance with weight as the covariate, a robust method for 
comparison of groups with divergent body weight and composition ${ }^{36}$. High-fat diet consisting of $45 \%$ calories from fat (D12451, Research Diets, NJ, USA) was used for the calorimetric study as the consistency of the $60 \%$ fat diet is not compatible with the food hoppers in the measurement system.

Serum biochemistry. Murine serum triglycerides and glucose concentrations were measured using Triglyceride E-test kit and glucose CII kit, respectively (Wako chemicals, Osaka Japan), according to the manufacturer's instructions. Serum insulin levels were measured using ultrasensitive ELISA kit (Morinaga, Yokohama, Japan) according to the manufacturer's instruction.

Microarray. The four RNA sources, WT scWAT, $\mathrm{LrI1}^{-/-}$scWAT, WT BAT and $\mathrm{Lr}_{11}{ }^{-1-}$ BAT, were prepared from subcutaneous WAT and BAT from WT mice and $\mathrm{LrI1}^{-/-}$mice, respectively $(n=3$ each). Microarray analyses were performed by Takara Bio (Japan). Briefly, cyanine-3-labelled cRNA was prepared from $0.1 \mu \mathrm{g}$ total RNA using the Low Input Quick Amp Labeling kit (Agilent) according to the manufacturer's instructions, followed by RNAeasy column purification (QIAGEN, Valencia, CA). Dye incorporation and cRNA yield were checked with the NanoDrop ND-2000 Spectrophotometer. An amount of $0.6 \mu \mathrm{g}$ of cyanine-3-labelled cRNA was then fragmented at $60^{\circ} \mathrm{C}$ for $30 \mathrm{~min}$ in a reaction volume of $25 \mu \mathrm{l}$ containing $1 \times$ Agilent fragmentation buffer and $2 \times$ Agilent blocking agent following the manufacturer's instructions. On completion of the fragmentation reaction, $25 \mu \mathrm{l}$ of $2 \times$ Agilent hybridization buffer was added to the fragmentation mixture and hybridized to Agilent Mouse GE $8 \times 60 \mathrm{~K}$ Microarray for $17 \mathrm{~h}$ at $65^{\circ} \mathrm{C}$ in a rotating Agilent hybridization oven. After hybridization, microarrays were washed 1 min at room temperature with GE Wash Buffer 1 (Agilent) and 1 min at $37^{\circ} \mathrm{C}$ GE Wash buffer 2 (Agilent), then dried immediately by brief centrifugation. Slides were scanned immediately after washing on the Agilent DNA Microarray Scanner (G2565CA) using one colour scan setting for $8 \times 60 \mathrm{k}$ array slides (scan area $61 \times 21.6 \mathrm{~mm}$, scan resolution $3 \mu \mathrm{m}$, dye channel is set to Green PMT to $100 \%)$. The scanned images were analysed with Feature Extraction Software 10.10 (Agilent) using default parameters to obtain background-subtracted and spatially detrended processed signal intensities. The gene-tree analysis revealed six clusters based on the expression pattern of the four RNA sources. The gene expression pattern with Cluster 6: WT scWAT $<$ Lr11 ${ }^{-1}-\operatorname{scWAT}<$ or $=$ WT BAT $=$ or $<\mathrm{LrI1}^{-/}-\mathrm{BAT}$ was dominant compared with other patterns. The top 100 genes of $\mathrm{LrI1}^{-1-}$ scWAT > WT scWAT in cluster 6 were listed and summarized (Supplementary Table 2).

Quantitative PCR with reverse transcription. Total RNA was isolated from cells or using Buffer RLT and purified by RNeasy Mini columns (Qiagen). RNA was isolated from ground tissues using STAT-60 reagent (TEL-TEST) followed by chloroform extraction and isopropanol precipitation. Complimentary DNA was generated from $500 \mathrm{ng}$ of RNA using M-MLV reverse transcriptase and master mix (Promega) in a $20 \mu \mathrm{l}$ reaction mixture with $2.5 \mathrm{mM} \mathrm{MgCl}, 1.25 \mathrm{mM}$ dNTPs and $5 \mu \mathrm{g} \mathrm{ml}^{-1}$ random hexamers at $37^{\circ} \mathrm{C}$ for $1 \mathrm{~h}$. Complementary DNA was diluted 75 -fold and $5 \mu \mathrm{l}$ of diluted complementary DNA was used in a $12 \mu \mathrm{l}$ real-time PCR reaction mixture using TaqMan primers and probes or SYBR green reagent (Applied Biosystems) according to manufacturer's instructions. Reactions were run in duplicate for each sample and quantified in the ABI Prism 7900 sequence detection system (Applied Biosystems). Data are expressed as arbitrary units where expression of target genes are corrected using the geometric average of four housekeeping genes: 18S, $\beta 2$-microglobulin, $\beta$-actin and 36B4 using Bestkeeper (freeware). Sequences of primers and probes used are listed in Supplementary Table 3.

Tissue collection and histology. All animal tissues for protein or RNA extraction were snap frozen in liquid nitrogen at the time of collection unless otherwise stated and later ground to a fine powder using a sterile pestle and mortar on liquid nitrogen. Samples for histology were placed in $10 \%$ buffered formalin overnight before transfer to $70 \%$ ethanol and later embedding in paraffin. Multiple sections were stained with haematoxylin and eosin for morphological analysis.

Immunohistochemistry. Paraffin-embedded sections $(5 \mu \mathrm{m})$ were used for immunohistostaining. Deparaffinized sections were pretreated with $0.3 \% \mathrm{H}_{2} \mathrm{O}_{2}$ to inactivate endogenous peroxidase. Slides were stained in the presence of $3 \%$ bovine serum albumin (BSA) with antibody against UCP1 (1:50 dilution) at $23^{\circ} \mathrm{C}$ for $1 \mathrm{~h}$ followed by horseradish peroxidase-conjugated anti-rabbit IgG secondary antibodies (Molecular Probes) at 1:200 dilution. The slides were counterstained with haematoxylin. Controls with non-immune rabbit IgG were conducted in parallel with each immunoassay procedure.

Western blot. Powdered tissue or collected cultured cells were resuspended in lysis buffer (20 mM Tris-HCL, $150 \mathrm{mM} \mathrm{NaCl}, 1 \mathrm{mM}$ EGTA, $1 \mathrm{mM}$ EDTA, $1 \%$ Triton X-100, pH7.5) with added protease and phosphatase inhibitor cocktails according to manufacturers instruction (Sigma). After lysis, lysates were cleared by centrifugation at $10000 \mathrm{~g}$ for $10 \mathrm{~min}$ at $4^{\circ} \mathrm{C}$. Protein concentrations of the supernatants were determined by $\mathrm{D}_{\mathrm{c}}$ Protein assay (Bio-Rad). Proteins were diluted in Laemmli buffer with $1 \% 2$-mercaptoethanol. Proteins $(20 \mu \mathrm{g})$ were separated by SDS-polyacrylamide gel (10\%) electrophoresis and transferred to Immobilon-P membrane using a semi-dry transfer apparatus (Biorad). Membranes were blocked for $1 \mathrm{~h}$ at room temperature and incubated overnight at $4{ }^{\circ} \mathrm{C}$ with the indicated antibody. Bound primary antibodies were detected using peroxidase-coupled secondary antibodies and enhanced chemiluminescence (Amersham). Relative quantification of band intensities was calculated by digitally photographing exposed films and using Genesnap and Genetools software (Syngene). Uncropped scans of blots are shown in Supplementary Fig. 2.

SMAD assays. Cultured fully differentiated adipocytes derived from the subcutaneous fat tissues of wild-type or Lr11 ${ }^{-/-}$mice in the presence of BMP7 for the first 2 days were prepared. After serum depletion for $16 \mathrm{~h}$, the cells were incubated with or without $3.3 \mathrm{nM} \mathrm{BMP7}$ or $2 \mathrm{ng} \mathrm{ml}^{-1}$ TGF-b in the presence or absence of $10 \mathrm{ng} \mathrm{ml}^{-1}$ sLR11 for $30 \mathrm{~min}$, and then collected for the following western blot analyses. Cells were washed three times with phosphate-buffered saline (PBS) and harvested in RIPA buffer containing $0.01 \mathrm{mM}$ APMSF. For immunoblotting, equal amounts of solubilized protein was subjected to $10 \%$ SDS - polyacrylamide gel after heating to $95^{\circ} \mathrm{C}$ for $5 \mathrm{~min}$ under reducing conditions and transferred to a nitrocellulose membrane.

Immunoprecipitation. An amount of $100 \mu \mathrm{g}$ of membrane protein was mixed with $1 \mu \mathrm{g}$ of anti-human LR11 antibody M3 or control IgG, and rotated for $1 \mathrm{~h}$ at $4{ }^{\circ} \mathrm{C}$. The LR11/BMPRs/antibody complex was precipitated by protein A Sepharose. The proteins were released into $25 \mu \mathrm{l}$ SDS sample buffer by heating to $95^{\circ} \mathrm{C}$ for $10 \mathrm{~min}$ and applied for western blot analysis using anti-BMPR1A, BMPR1B or BMPR2 antibody as described.

Antibodies and recombinant and purified proteins. Monoclonal antibodies against phospho-SMAD1/5/8 (\#9511, Lot\#14, 1:1,000), SMAD3 (\#C25A9, Lot\#13, 1:1,000) and BMPR2 (\#6979, Lot\#1, 1:1,000) were obtained from Cell Signaling. Monoclonal antibodies against BMPR1A (MAB2406, Lot\#UEJ0112071, $1 \mathrm{gg} \mathrm{ml}^{-1}$ ) and BMPR1B (MAB505, Lot\#DGD0410091, $1 \mu \mathrm{g} \mathrm{ml}^{-1}$ ) were obtained from R\&D Systems. Monoclonal Antibody to $\beta$-Actin was obtained from Sigma Aldrich (\#A2228, Lot\#052M4816V, 1:1,000). Rabbit polyclonal antibody against UCP1 was obtained from Abcam (ab23841, Lot\#GR34748-1, $5 \mu \mathrm{g} \mathrm{ml}^{-1}$ ). Recombinant human BMP7 (354-BP, Lot\#EOS1914031, $3 \mathrm{nMl}^{-1}$ ) was obtained from R\&D Systems. Soluble form of LR11 protein (sLR11) was purified from the medium incubated with Colo201 (B226, JCRB Cell Bank, Osaka, Japan) by affinity column using monoclonal antibody against sLR11, followed gel filtration as previously described $^{20}$. Purified sLR11 was concentrated and used for experiments at a concentration of $10 \mathrm{ng} \mathrm{ml}^{-1}$, estimated from its biological activity in stimulating the migration of smooth muscle cells as previously described ${ }^{11}$.

Culture of adipocytes. Mouse primary adipocytes were obtained from either BAT or subcutaneous WAT by excision of the fat pad followed by mincing with sterile surgical scissors and digestion at $37^{\circ} \mathrm{C}$ with shaking for $\sim 35 \mathrm{~min}(10 \mathrm{ml}$ Hanks buffered salt solution, $2 \%$ BSA, $2 \mathrm{mg} \mathrm{ml}^{-1}$ Type 2 collagenase (C6885, Sigma). Digests were filtered through a $100 \mu \mathrm{M}$ filter and left to sit on ice for $10 \mathrm{~min}$. The upper fat layer was removed and then the upper $2 / 3$ of the supernatant washed twice in PBS before being plated. Cells were maintained and differentiated in Dulbecco's modified Eagle's medium with $10 \%$ fetal bovine serum, $20 \mathrm{mM}$ L-glutamine, 100 units $\mathrm{ml}^{-1}$ penicillin and $100 \mu \mathrm{g} \mathrm{ml}^{-1}$ streptomycin with $150 \mu \mathrm{M}$ sodium ascorbate and $4 \mathrm{nM}$ insulin in the presence of $1 \mathrm{nM} \mathrm{3,3} 3^{\prime}, 5$-Triiodo-Lthyronine at $37^{\circ} \mathrm{C}$ in $5 \% \mathrm{CO}_{2}$. After 8 days, cells were fully differentiated (validated by gene expression profiles and morphological appearance), and if BMP7 and/or sLR11 were added, $3.3 \mathrm{nM}$ BMP7 was present in the culture media for the first 2 days and/or $10 \mathrm{ng} \mathrm{ml}^{-1} \mathrm{sLR} 11$ was present throughout the culture period. Cultures were routinely tested for the presence of mycoplasma contamination and decontamination/rederivation performed when necessary. Human primary preadipocytes were prepared from the stromal vascular fraction of fat tissues and cultured as described $^{37}$. The procedures were approved by the Ethical Committee on human study, Toho University Sakura Medical Center.

Transfection of cultured brown adipocytes with siRNA. Cultured brown adipocytes were transfected with siRNA (25 nM) specific for BMPR1A (L-040598-000005, Dharmacon, GE healthcare) or BMPR1B (L-051071-00-0005, Dharmacon), or with control siRNA (D-001810-10-05, Dharmacon) for 3 days according to manufacturer's instruction protocol (https://dharmacon.gelifesciences.com/uploadedFiles/Resources/basic-dharmafect-protocol.pdf) for the siRNA transfection reagent (T-2001-01, Dharmacon), and then incubated with differentiation media for mature brown adipocytes for 2 days. After serum depletion for $16 \mathrm{~h}$, the cells were incubated with or without sLR11 at $10 \mathrm{ng} \mathrm{ml}^{-1}$ for $2 \mathrm{~h}$, and used for real-time PCR analyses.

Cell lines. Hek 293 cells were obtained from Sigma (product number 85120602). While cells were not independently authenticated, this was not a major concern as they were used only for the luciferase reporter assays and have been routinely used 
in our laboratory for multiple previous similar experiments without problems. Grossly the cells behaved as expected in terms of their growth and morphology and their viability and transfection efficiency were found to be excellent. As for primary cultures, cultures were routinely screened for mycoplasma contamination.

LPL activity assay. This assay was performed as previously described ${ }^{38}$. Briefly, the culture medium for adipocytes cultured for $16 \mathrm{~h}$ without fetal bovine serum were collected and the LPL activity was measured as below using triolein (Sigma, St Louis, MO) as the substrate. The substrate solution was prepared as follows: $100 \mathrm{mg}$ of triolein and $7.5 \mathrm{ml}$ of $0.2 \%$ Triton X-100 at a final volume of $7.5 \mathrm{ml}$ of 1 mole $^{-1}$ Tris-HCl (pH 8.0) were sonicated on ice for $10 \mathrm{~min}$. The LPL activity assay reaction mixture contained $50 \mu \mathrm{l}$ of substrate solution, $25 \mu \mathrm{l}$ of $20 \%$ fatty acidfree bovine serum albumin ( $\mathrm{pH}$ 8.0; Sigma), $5 \mu \mathrm{l}$ of $\mathrm{HDL}\left(3 \mathrm{mg}\right.$ protein $\mathrm{ml}^{-1}$ ) as a source of apo C-II and $100 \mu \mathrm{l}$ of sample. After incubation for $2 \mathrm{~h}$ at $37^{\circ} \mathrm{C}$, the enzyme reaction was terminated by the addition of $10 \mu \mathrm{l}$ of di-

isopropylfluorophosphate. The amount of free-fatty acids released in the mixture was measured at $4^{\circ} \mathrm{C}$ using an enzymatic method (Nescauto NEFA V2; Alfresa Pharma, Osaka, Japan).

Cellular respiration. Differentiated primary adipocytes were placed in a XF24 bioanalyser (Seahorse Bioscience, MA, USA) in the manufacturer's designated culture/assay plate (each plate was seeded with an equal number of cells from a pool of primary adipocytes from two animals). Basal cellular respiration was measured over a period of $15 \mathrm{~min}$ using the oxygen consumption rate (OCR) measurement assay template. An amount of $100 \mathrm{nM} \mathrm{NE}$ was then added to the assay medium (XF assay medium, Seahorse) and respiration measured for a further 15 min using OCR measurement template. Basal and stimulated oxygen consumptions reported are the mean of three separate OCR measurements per well.

NE-induced thermogenesis. Two individually housed mice (litter mates) were monitored simultaneously at an airflow of $11 \mathrm{~min}^{-1}$. HFD-fed mice housed at thermoneutrality for 8 weeks before assessment were anaesthetized with pentobarbital $\left(45 \mathrm{mg} \mathrm{kg}^{-1}\right.$ i.p.). The oxygen consumption and carbon dioxide production of the mice was measured at $30^{\circ} \mathrm{C}$ to obtain basal values during $15 \mathrm{~min}$. Thereafter the mice were removed from the metabolic chambers for $6 \mathrm{~min}$ and injected subcutaneously with NE $\left(1 \mathrm{mg} \mathrm{kg}^{-1}\right)$ before being returned to the metabolic chambers for $45 \mathrm{~min}$. Energy expenditure was calculated as described above but presented as the fold increase or mean increase, thus not requiring covariate analysis.

Clinical study. Study 1 subjects consisted of 156 consecutive patients with sleep apnoea syndrome and study 2 consisted of 25 consecutive patients with type 2 diabetes mellitus or glucose intolerance-associated metabolic disorders at Toho University Sakura Medical Center or Yanbian University Hospital. Blood samples were collected in the morning after an overnight fast, and the biochemical data were measured using standard hospital laboratory techniques. The potential risk factors for diabetes and atherosclerosis were analysed, including age, sex, BMI, VFA and SFA, blood lipids and HbAlc for both studies; smoking, medication of diabetes, medication of hypertension, medication of dyslipidemia, history of coronary artery disease and history of cerebrovascular diseases for Study 1; fasting plasma glucose and systolic and diastolic blood pressures for Study 2. In Study 3, 14 obese subjects received bariatric surgery at Toho University Sakura Medical Center, and their VFA and SFA were measured before and 12 months after the surgery. The body weights of all patients decreased 1 year after surgery compared with those before surgery. Visceral fat areas and SFA were measured at umbilical levels of patients using computed tomography. Hypertension was defined as systolic pressure of more than $140 \mathrm{~mm} \mathrm{Hg}$ or diastolic pressure of more than $90 \mathrm{~mm} \mathrm{Hg}$. Diabetes mellitus was defined as a fasting blood glucose level of more than $126 \mathrm{mg} \mathrm{dl}^{-1}$, glycosylated haemoglobin (HbAlc) of more than $6.2 \%$, or both. Dyslipidemia was defined as serum total cholesterol of more than $220 \mathrm{mg} \mathrm{dl}^{-1}$ and triglycerides of more than $150 \mathrm{mg} \mathrm{dl}^{-1}$ in the fasting state, or both, and HDL cholesterol $<40 \mathrm{mg} \mathrm{dl}^{-1}$, or a combination thereof. The patients suffering from possible malignant diseases, Alzheimer's disease, renal diseases or hepatic diseases were excluded in the study subjects. The procedures of the above human studies were approved by the Human Investigation Review Committee on human study, Toho University Sakura Medical Center or Yanbian University Hospital. Informed consent was obtained from all subjects.

sLR11 measurement. Serum sLR11 concentrations were determined using a sandwich ELISA system. $12.5 \mu \mathrm{l}$ of human and $2.5 \mu \mathrm{l}$ of murine serum were used for the measurement of sLR11 by respective ELISA. Human serum sLR11 concentrations were determined using a revised procedure based on sandwich ELISA system previously reported ${ }^{39}$. In brief, $12.5 \mu$ l of human serum were diluted eightfold with $1 \%$ BSA in PBS containing 0.1\% Tween 20 (PBST), reacted with the capture anti-LR11mouse monoclonal antibody $\mathrm{M} 3 \mathrm{~F}\left(\mathrm{ab}^{\prime}\right) 2$ for $2 \mathrm{~h}$, then incubated with a biotinylated capture anti-LR11 rat monoclonal antibody R1 for $1 \mathrm{~h}$. A murine serum soluble LR11 ELISA was performed using two mouse monoclonal antibodies, Mab93222 and Mab93213 that were established by immunization of $\mathrm{Lr}_{1}{ }^{-/}$- mice using synthetic peptides against different epitopes of VPS10p domain of LR11 protein ${ }^{40}$. Briefly, $2.5 \mu \mathrm{l}$ of murine serum were diluted 20 -fold with $1 \%$ BSA in PBST, reacted with the capture Mab93222 for $2 \mathrm{~h}$, and then incubated with the biotinylated capture Mab93213 for 1 h. The LR11-antibody complex was quantified with horseradish peroxidase-conjugated streptavidin using purified human and rabbit LR11 protein as a standard.

Power calculations. Group sizes were calculated using STPLAN software created by Barry Brown from the University of Texas MD Anderson Cancer Center. We have used mean values and standard deviations obtained from preliminary data from studies in $\mathrm{LrI1}^{-/-}$mice. In this instance we expected effect sizes ranging down to $30 \%$ and aimed to obtain statistical significance of $P<0.05$ at a power of 0.9 . With the expected s.d. of up to $12 \%$ and thus planned to include a minimum of seven animals/group for in vivo studies.

Exclusion criteria. Animals were excluded if their phenotypic characteristic fell more than two s.d. from the mean of the group. In practice only two animals were excluded from two separate parts of this study.

Randomization and blinding. No formal randomization was applied, but for diet studies, animals of each genotype were grouped so as to match mean starting bodyweights of chow and HFD groups. The researchers were not blinded as to the genotype of the animals as this was not practical because of the weight divergence phenotype. All measurement of gene expression and serum biochemistry was conducted by a researcher who was blinded for the experimental groups' identities.

Statistics. Statistical analysis was performed with SPSS statistics version 23 (IBM) or Stat Flex v. 5.0 (Artech). Data was tested for normality and a Levene test for equality of variance was also applied to all data sets before parametric tests were applied. $P$ values were not applied to exploratory initial studies where only the nul hypothesis was being tested, only where an a priori hypothesis had been defined and informed the study. Associations of sLR11 levels with risk factors were examined by Pearson correlation analysis for continuous variables and by unpaired $t$-test for categorical variables between groups (sex, smoking, medication of diabetes, hypertension or dyslipidemia and history of coronary artery disease or cerebrovascular disease). The study subjects were principally separated to two groups based on the averaged values. In clinical studies, multiple linear regression analyses were used to calculate coefficient beta for sLR11 by controlling for age, smoking, HDL-cholesterol, HbA1c, BMI, VFA and SFA for study 1, and VFA and SFA for the study of patients that received bariatric surgery (study 3), which are significantly correlated with sLR11.

\section{References}

1. Bostrom, P. et al. A PGC1-alpha-dependent myokine that drives brown-fat-like development of white fat and thermogenesis. Nature 481, 463-468 (2012).

2. Leonardsson, G. et al. Nuclear receptor corepressor RIP140 regulates fat accumulation. Proc. Natl Acad. Sci. USA 101, 8437-8442 (2004).

3. Whittle, A. J. et al. BMP8B increases brown adipose tissue thermogenesis through both central and peripheral actions. Cell 149, 871-885 (2012).

4. Cypess, A. M. et al. Identification and importance of brown adipose tissue in adult humans. N. Engl. J. Med. 360, 1509-1517 (2009).

5. Nedergaard, J., Bengtsson, T. \& Cannon, B. Unexpected evidence for active brown adipose tissue in adult humans. Am. J. Physiol. Endocrinol. Metab. 293, E444-E452 (2007).

6. Zingaretti, M. C. et al. The presence of UCP1 demonstrates that metabolically active adipose tissue in the neck of adult humans truly represents brown adipose tissue. FASEB J. 23, 3113-3120 (2009).

7. Ouellet, V. et al. Outdoor temperature, age, sex, body mass index, and diabetic status determine the prevalence, mass, and glucose-uptake activity of 18F-FDGdetected BAT in humans. J. Clin. Endocrinol. Metab. 96, 192-199 (2011).

8. Lee, P. et al. Temperature-acclimated brown adipose tissue modulates insulin sensitivity in humans. Diabetes 63, 3686-3698 (2014).

9. Whittle, A. Searching for ways to switch on brown fat: are we getting warmer? J. Mol. Endocrinol. 49, R79-R87 (2012).

10. Dodson, S. E. et al. Loss of LR11/SORLA enhances early pathology in a mouse model of amyloidosis: evidence for a proximal role in Alzheimer's disease. J. Neurosci. 28, 12877-12886 (2008).

11. Jiang, M. et al. Ang II-stimulated migration of vascular smooth muscle cells is dependent on LR11 in mice. J. Clin. Invest. 118, 2733-2746 (2008).

12. Ohwaki, K. et al. A secreted soluble form of LR11, specifically expressed in intimal smooth muscle cells, accelerates formation of lipid-laden macrophages. Arterioscler. Thromb. Vasc. Biol. 27, 1050-1056 (2007).

13. Taira, K. et al. LR11, a mosaic LDL receptor family member, mediates the uptake of ApoE-rich lipoproteins in vitro. Arterioscler. Thromb. Vasc. Biol. 21, 1501-1506 (2001).

14. Bartelt, A. et al. Brown adipose tissue activity controls triglyceride clearance. Nat. Med. 17, 200-205 (2011).

15. Klinger, S. C. et al. SorLA regulates the activity of lipoprotein lipase by intracellular trafficking. J. Cell. Sci. 124, 1095-1105 (2011).

16. Nishii, K. et al. The soluble form of LR11 protein is a regulator of hypoxiainduced, urokinase-type plasminogen activator receptor (uPAR)-mediated adhesion of immature hematological cells. J. Biol. Chem. 288, 11877-11886 (2013).

17. Kanaki, T. et al. Developmental regulation of LR11 expression in murine brain. DNA Cell Biol. 17, 647-657 (1998). 
18. Crossno, Jr. J. T., Majka, S. M., Grazia, T., Gill, R. G. \& Klemm, D. J. Rosiglitazone promotes development of a novel adipocyte population from bone marrowderived circulating progenitor cells. J. Clin. Invest. 116, 3220-3228 (2006).

19. Feldmann, H. M., Golozoubova, V., Cannon, B. \& Nedergaard, J. UCP1 ablation induces obesity and abolishes diet-induced thermogenesis in mice exempt from thermal stress by living at thermoneutrality. Cell Metab. 9, 203-209 (2009).

20. Matsuo, M. et al. Development of an immunoassay for the quantification of soluble LR11, a circulating marker of atherosclerosis. Clin. Chem. 55, 1801-1808 (2009).

21. Cannon, B. \& Nedergaard, J. Brown adipose tissue: function and physiological significance. Physiol. Rev. 84, 277-359 (2004).

22. Boon, M. R. et al. BMP7 activates brown adipose tissue and reduces dietinduced obesity only at subthermoneutrality. PLOS ONE 8, e74083 (2013).

23. Schulz, T. J. et al. Brown-fat paucity due to impaired BMP signalling induces compensatory browning of white fat. Nature 495, 379-383 (2013).

24. Schulz, T. J. et al. Identification of inducible brown adipocyte progenitors residing in skeletal muscle and white fat. Proc. Natl Acad. Sci. USA 108, 143-148 (2011)

25. Tseng, Y. H. et al. New role of bone morphogenetic protein 7 in brown adipogenesis and energy expenditure. Nature 454, 1000-1004 (2008).

26. Bohm, C. et al. SorLA signaling by regulated intramembrane proteolysis. J. Biol. Chem. 281, 14547-14553 (2006).

27. Werling, M. et al. Increased postprandial energy expenditure may explain superior long term weight loss after Roux-en-Y gastric bypass compared to vertical banded gastroplasty. PLoS ONE 8, e60280 (2013).

28. Faria, S. L., Faria, O. P., Cardeal Mde, A., Ito, M. K. \& Buffington, C. Dietinduced thermogenesis and respiratory quotient after Roux-en-Y gastric bypass surgery: a prospective study. Surg. Obes. Relat. Dis. 10, 138-143 (2014).

29. Pottier, C. et al. High frequency of potentially pathogenic SORL1 mutations in autosomal dominant early-onset Alzheimer disease. Mol. Psychiatry 17, 875-879 (2012).

30. Takahashi, M. et al. Enhanced circulating soluble LR11 in patients with coronary organic stenosis. Atherosclerosis 210, 581-584 (2010).

31. Whittle, A., Relat-Pardo, J. \& Vidal-Puig, A. Pharmacological strategies for targeting BAT thermogenesis. Trends Pharmacol. Sci. 34, 347-355 (2013).

32. Christian, M. et al. RIP140-targeted repression of gene expression in adipocytes. Mol. Cell. Biol. 25, 9383-9391 (2005).

33. Gerhart-Hines, Z. et al. The nuclear receptor Rev-erbalpha controls circadian thermogenic plasticity. Nature 503, 410-413 (2013).

34. Virtue, S., Even, P. \& Vidal-Puig, A. Below thermoneutrality, changes in activity do not drive changes in total daily energy expenditure between groups of mice. Cell Metab. 16, 665-671 (2012).

35. Elia, M. \& Livesey, G. Energy expenditure and fuel selection in biological systems: the theory and practice of calculations based on indirect calorimetry and tracer methods. World Rev. Nutr. Diet. 70, 68-131 (1992).

36. Arch, J. R., Hislop, D., Wang, S. J. \& Speakman, J. R. Some mathematical and technical issues in the measurement and interpretation of open-circuit indirect calorimetry in small animals. Int. J. Obes. (Lond.) 30, 1322-1331 (2006).

37. Asada, S. et al. Ceiling culture-derived proliferative adipocytes retain high adipogenic potential suitable for use as a vehicle for gene transduction therapy. Am. J. Physiol. Cell. Physiol. 301, C181-C185 (2011).

38. Murano, T., Sako, T., Oikawa, S. \& Shirai, K. The recovery of dysfunctional lipoprotein lipase (Asp204-Glu) activity by modification of substrate. Atherosclerosis 183, 101-107 (2005).

39. Fujimura, K. et al. Circulating LR11 is a novel soluble-receptor marker for early-stage clinical conditions in patients with non-Hodgkin's lymphoma. Clin. Chim. Acta 430, 48-54 (2014).
40. Nakata, Z. et al. Crystallization and preliminary crystallographic analysis of human LR11 Vps10p domain. Acta. Crystallogr. Sect. F Struct. Biol. Cryst. Commun. 67, 129-132 (2011).

\section{Acknowledgements}

A.J.W. and A.V.P. were supported by FP7-BetaBAT, BBSRC (BB/J009865/1), the British Heart Foundation (PG/12/53/29714) and MDU MRC. M.J. and H.B. were supported by Japan Health and Labour Sciences Research grants for translational research (H22rinkensui-ippan-001) and US-Japan cooperative medical science program. They were also supported by Grants-in-aid for Scientific Research (24390231, 26461369, and $15 \mathrm{~K} 15198)$, and the supported program for the strategic research foundation at private universities from the Japanese Ministry of Education, Culture, Sports, Science and Technology. V.P. was supported by Wellcome Trust and the Cambridge Overseas Trust. J.R. was supported by Ministerio de Educación, through "Programa Nacional de Movilidad de Recursos Humanos del Plan Nacional de I-D + i 2008-2011 (Subprograma de Estancias de Movilidad en el Extranjero 'José Castillejo' para jóvenes Doctores, ref: JC2011-0248). S.V. was supported by MRC. W.J.S. was supported by the Austrian Science Fund (FWF P-20218 and P-20455). Animal work was performed at the MDU DMC Core facilities.

\section{Author contributions}

A.J.W. wrote the manuscript, performed in vivo metabolic phenotyping of $L R 11^{-/}$ mice and characterized the role of sLR11 on cellular respiration. M.J. performed initial characterization of the $L R 11^{-/-}$mice, in vitro signalling studies and statistical analyses. V.P. assisted with in vivo experiments. J.R. performed lipolysis and reporter assays. S.V. assisted with in vivo metabolic phenotyping. H.E. and I.F. prepared the recombinant sLR11 and measured sLR11 levels in samples. T.Y. and I.T. oversaw clinical studies 2 and 3. Mao T. oversaw clinical study 1. T.M. performed LPL measurements. Mas. T. and C.N managed further in vivo experiments to assess changes to sLR11 levels. W.J. and Z.J. managed clinical studies 2 and 3. M.C. performed gene expression analyses. W.J.S. designed experimental protocols and assisted with the manuscript preparation. A.V.P. managed all work undertaken at Cambridge and provided scientific guidance throughout the project. H.B. managed all work coordinated outside of Cambridge and provided scientific guidance throughout the project.

\section{Additional information}

Accession codes: Microarray data have been deposited in the NCBI Gene Expression Omnibus (GEO) under accession codes GSE69117.

Supplementary Information accompanies this paper at http://www.nature.com/ naturecommunications

Competing financial interests: The authors declare no competing financial interests.

Reprints and permission information is available online at http://npg.nature.com/ reprintsandpermissions/

How to cite this article: Whittle, A. J. et al. Soluble LR11/SorLA represses thermogenesis in adipose tissue and correlates with BMI in humans. Nat. Commun. 6:8951 doi: $10.1038 /$ ncomms 9951 (2015)

This work is licensed under a Creative Commons Attribution 4.0 International License. The images or other third party material in this article are included in the article's Creative Commons license, unless indicated otherwise in the credit line; if the material is not included under the Creative Commons license, users will need to obtain permission from the license holder to reproduce the material To view a copy of this license, visit http://creativecommons.org/licenses/by/4.0/ 